


\section{Boas práticas de manipulação na comercialização do camarão fresco em feiras livres de Belém, PA}

Good handling practices of fresh shrimp sold in street fairs of Belém, PA, Brazil

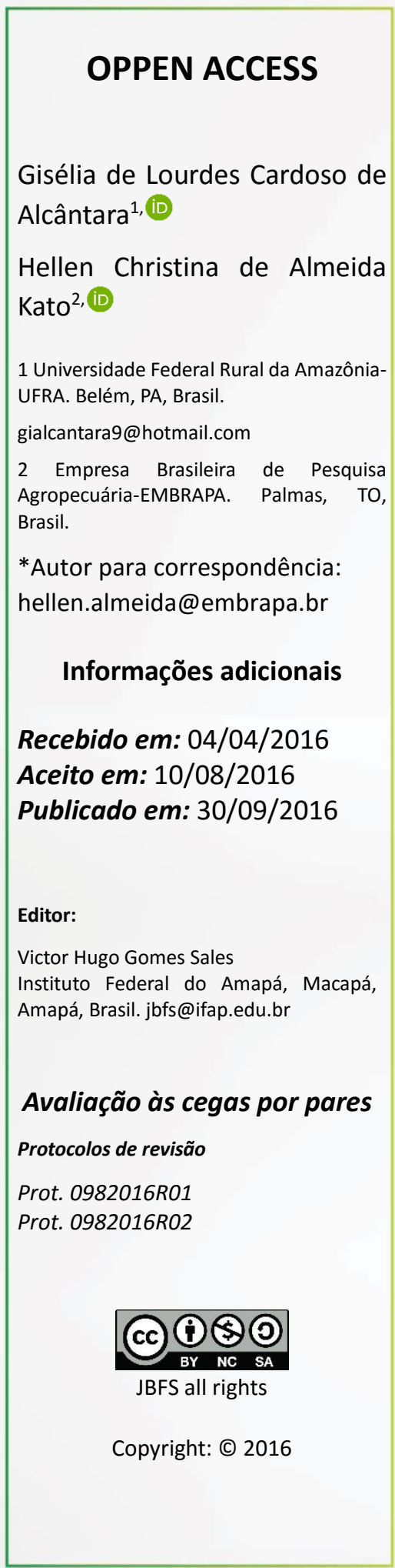

\begin{abstract}
ID JBFS0982016
DOI 10.18067/jbfs.v3i3.98

\section{RESUMO}

A aplicação de boas práticas de manipulação entre feirantes que comercializam pescado na Amazônia é fundamental, devido aos hábitos de consumo alimentar regionais e da preferência pela aquisição de alimentos em feiras livres e mercados. Esta pesquisa teve como objetivo avaliar as condições de comercialização do camarão (Macrobrachium amazonicum) fresco inteiro em diferentes feiras livres e mercados de Belém por meio de uma lista de verificação produzida de acordo com o que preconiza a Legislação Brasileira para o pescado fresco inteiro. Foram visitadas sete feiras e três mercados da região metropolitana de Belém, onde sessenta vendedores de camarão regional fresco foram entrevistados com apoio de um questionário baseado na legislação brasileira incluindo parâmetros de condições ambientais das feiras, aspectos gerais de recursos humanos dos manipuladores, equipamentos e utensílios, higienização e por fim, aspectos gerais de exposição. Na observação realizada neste trabalho $100 \%$ dos estabelecimentos apresentaram não conformidades em pelo menos um dos parâmetros analisados, denotando assim a urgência de políticas públicas visando a capacitação de feirantes em boas práticas de manipulação como política de promoção de saúde pública.
\end{abstract}

Palavras-chave: Higiene. Manipuladores. Pescado. Macrobrachium amazonicum

\section{ABSTRACT}

The application of good handling practices among market traders who sell fish in the Amazon region is a critical situation, due to consumption regional habits and preference for food acquisition in street fair and traditional markets. This research aimed to evaluate the fresh shrimp (Macrobrachium amazonicum) selling conditions in different street fairs and markets of Belém using a checklist based on the Brazilian legislation that refers to whole fresh fish. Seven fairs and three markets were visited in the metropolitan area ofBelém, where sixty vendors of fresh regional shrimp were interviewed with the help of a questionnaire that included parameters of environmental conditions of the selling, general aspects of human resources of the handlers, equipment and utensils, sanitization, and finally, general aspects of exposure. In the observation made by this research, $100 \%$ of the establishments had non-conformities in at least one of the parameters analyzed, thus indicating the urgency of public policies aimed at training in good handling practices to this target public as a health promotion policy.

Keywords: Hygiene. Handlers. Fish. Macrobrachium amazonicum. 


\section{INTRODUÇÃO}

O camarão-da-amazônia, Macrobrachium amazonicum, é o decapoda de água doce com a grande importância econômica da região leste da América do Sul, ${ }^{1}$ tendo sido capturados pela pesca extrativa marinha do Brasil em 2011, 10.331,2 toneladas. ${ }^{2}$ Sua ampla exploração pesqueira, na região, deve-se ao volume de camarões encontrados e à boa aceitação no mercado consumidor. ${ }^{3}$ Segundo Lima, ${ }^{4}$ o destino da produção do extrativismo deste camarão no norte da Amazônia é distribuído para bares, restaurantes, supermercados, feiras livres e consumidores finais, principalmente nos estados do Pará e Amapá.

Depois de capturado, o pescado se deteriora gradualmente, pois é um alimento altamente perecível, devido a fatores como $\mathrm{pH}$ próximo da neutralidade, elevada atividade de água, teor de nutrientes facilmente utilizáveis por micro-organismos, alta atividade metabólica da biota microbiana que o acompanha e, principalmente, práticas inadequadas de manuseio. ${ }^{5}$ Portanto, a comercialização do pescado deve ser feita respeitando as Boas Práticas de Manipulação (BPM), preservando ao máximo suas características de frescor e a segurança alimentar da matéria-prima. As condições higiênicas do ambiente de manipulação e o cumprimento das exigências legais são fatores importantes na produção e comercialização segura desses alimentos com qualidade. ${ }^{6}$

Segundo o Regulamento Técnico de Identidade e Qualidade (RTIQ) para camarão fresco ${ }^{7}$ este produto deve caracterizar-se por matériaprima fresca, convenientemente lavada e conservada pelo resfriamento em temperaturas semeIhantes à do gelo fundente até sua comercialização.

A comercialização de pescados frescos em feiras livres e mercados públicos é uma forma importante do consumidor acessar o pescado dentro do comércio varejista. Barbosa et al. ${ }^{8}$ entrevistando 400 consumidores da cidade de Belém, descreveram que $68 \%$ dos entrevistados realizam a compra de pescados em feiras livres, pelo fato do preço ser mais atrativo. Além disso, o ambiente da feira facilita a verificação do frescor do pescado no momento da compra. Sendo assim, mercados e feiras livres são considerados locais tradicionais de comercialização de alimentos a varejo, sendo motivo de cautela frequente em virtude de deficiências higiênico-sanitárias comuns nesses ambientes. ${ }^{9}$

No entanto, sabe-se que as principais fontes de contaminação de alimentos são: matériaprima, ambiente e manipuladores. Os problemas encontrados nas feiras estão muitas vezes relacionados com as más condições higiênico-sanitárias dos pontos de comercialização, dos manipuladores e da forma como o produto é comercializado. ${ }^{10}$ Mercados e feiras livres da região metropolitana de Belém foram avaliados por Monteiro ${ }^{11}$ pesquisando as condições de comercialização da carne suína, ressaltando a falta de manutenção da cadeia de frio ou qualquer cuidado de cunho higiênico-sanitário. Os autores Correia e Roncada ${ }^{12}$ reforçam que a venda de alimentos em feiras, principalmente os de origem animal, pode levar a alterações na qualidade dos produtos, uma vez que esses ficam expostos nas barracas de forma inadequada sem refrigeração e sem proteção contra insetos e partículas presentes no ar.

Para garantir a segurança alimentar, órgãos como a Agência Nacional de Vigilância Sanitária (ANVISA) vinculada ao Ministério da Saúde regulamentam exigências mínimas que devem ser atendidas em ambientes de comercialização de alimentos, incluindo feiras e mercados. ${ }^{13}$ Essas exigências são parâmetros para Boas Práticas de Manipulação dos alimentos que abrangem desde instalações adequadas, estendendo-se até as regras de limpeza do local de trabalho e higiene pessoal, tais como a lavagem frequente e correta das mãos, utilização de uniformes adequados, disponibilização de materiais higiênicos e uso de sanitizantes apropriados, exposição e armazenamento dos alimentos. $^{14}$

A aplicação das BPM em ambientes de transformação agroindustrial de alimentos são a base de programas de autocontrole estabelecidos pelo $\mathrm{Mi}$ nistério da Agricultura, Pecuária e Abastecimento (MAPA). ${ }^{15}$ No caso das feiras, onde não há a exigência destes programas o domínio destas práticas e sua correta aplicação e verificação são o suporte para a prevenção de perigos físicos, químicos e biológicos, conservando a qualidade e segurança do produto para o consumidor final. ${ }^{16}$

Para avaliação do emprego de BPM é recomendado o uso da metodologia de aplicação de check list, ou seja, tabelas ou planilhas, onde se 
registram conformidade e não conformidades, de modo a facilitar a análise de dados e traçar um perfil do estabelecimento. ${ }^{17}$ Essa pesquisa teve como objetivo aplicar questionários (check list) para verificação das BPM do camarão fresco comercializado em mercados e feiras da região metropolitana de Belém, para identificação de não conformidades que ameacem a segurança alimentar da população e possam orientar ações educacionais e corretivas.

\section{MATERIAL E MÉTODOS}

A pesquisa foi realizada entre janeiro e agosto de 2014, período no qual foram visitadas sete feiras e três mercados da região metropolitana de Belém, e entrevistados seis manipuladores em cada local $(n=60)$, que também exerciam a função de vendedores de camarão regional fresco.

A avaliação das condições higiênico-sanitárias das feiras e mercados foi realizada com auxílio de um check list baseado nas recomendações da Resolução de Diretoria Colegiada (RDC) no 216 da Agência Nacional de Vigilância Sanitária. ${ }^{13}$ Os itens avaliados foram: Condições ambientais das feiras, os aspectos gerais de recursos humanos dos manipuladores, de equipamentos e utensílios, higienização e por fim os aspectos gerais de exposição. Em cada questionamento foi avaliado a Conformidade (C) ou ocorrência (Sim, S), Não Conformidade (NC) ou Não ocorrência (Não, N) ou item Não Aplicado (NA), através da declaração fornecida pelo entrevistado e observação in loco.

As respostas dos roteiros de observação foram transpostas para uma tabela no aplicativo PSPP 0.8.4 (Software livre, FSF Inc., 2013), constituindo assim um banco de dados, compilados em análises descritivas de frequências, além da correlação de Pearson entre os dados qualitativos coletados. Durante a entrevista foi pedida autorização para realização de material visual. Não foi necessário que esta pesquisa passasse por comitê de ética, já que se tratou de um estudo observacional.

\section{RESULTADOS E DISCUSSÃO}

Após a interpretação dos dados obtidos por meio do check list, destacou-se pontos chaves e a teorização das não-conformidades encontradas. As frequências encontradas no levantamento estão reunidas nas Figuras 1 a 3.
Dentre os entrevistados, $86,7 \%$ eram do sexo masculino e $13,3 \%$ do sexo feminino. A faixa etária predominante foi maior de 50 anos com $58,3 \%$ dos entrevistados, seguida da faixa 45-50 anos com $23,3 \%$ dos entrevistados. Quanto à escolaridade, $60 \%$ completaram o ensino fundamental e $31,7 \%$ tem o ensino fundamental incompleto.

Em relação aos aspectos gerais de recursos humanos foi verificado que $60 \%$ dos manipuladores entrevistados não passaram por treinamento em Boas Práticas de Manipulação, sendo que $40 \%$ que possuíam, não passaram por atualização nos últimos 12 meses, este resultado está ligado ao fato de $100 \%$ dos manipuladores terem apresentado alguma não conformidade relacionada à higiene pessoal.

É importante destacar que o perfil dos manipuladores investigados por essa entrevista se constitui de feirantes em idade avançada, em sua maioria maiores de 50 anos e de baixa escolaridade o que denota a importância de treinamentos voltados às características deste público-alvo em linguagem didática e objetiva.

O desconhecimento e a falta de treinamento adequado e contínuo aos manipuladores tornam-se uma barreira a ampliação de ferramentas de controle e garantia da segurança alimentar, que deveria ser buscada por governos em todas as suas esferas como ferramenta de promoção da saúde pública. Nóbrega et al. ${ }^{18}$ avaliando o aprendizado de BPM por comunidade de marisqueiras do Rio de Janeiro destacam que são essenciais atividades de educação e de formação continuada para soluções de limitações higiênico-sanitárias existentes, através do estabelecimento, reforço e monitoramento de princípios de higiene pessoal, dos alimentos e do ambiente.

Sendo assim, a deficiência na capacitação se reflete em todos os parâmetros de higiene avaliados. Nos aspectos relacionados à higiene pessoal do manipulador, identificou-se não conformidades em $100 \%$ dos estabelecimentos avaliados (Figura 1).

Falta de higiene com as mãos e unhas, vestimentas sujas, utilização de adornos e lesões expostas são não conformidades segundo a Portaria no $326^{19}$ que estabelece normas para o uso de equipamentos de proteção individual (EPI) descartáveis ou laváveis e práticas de higiene pessoal 


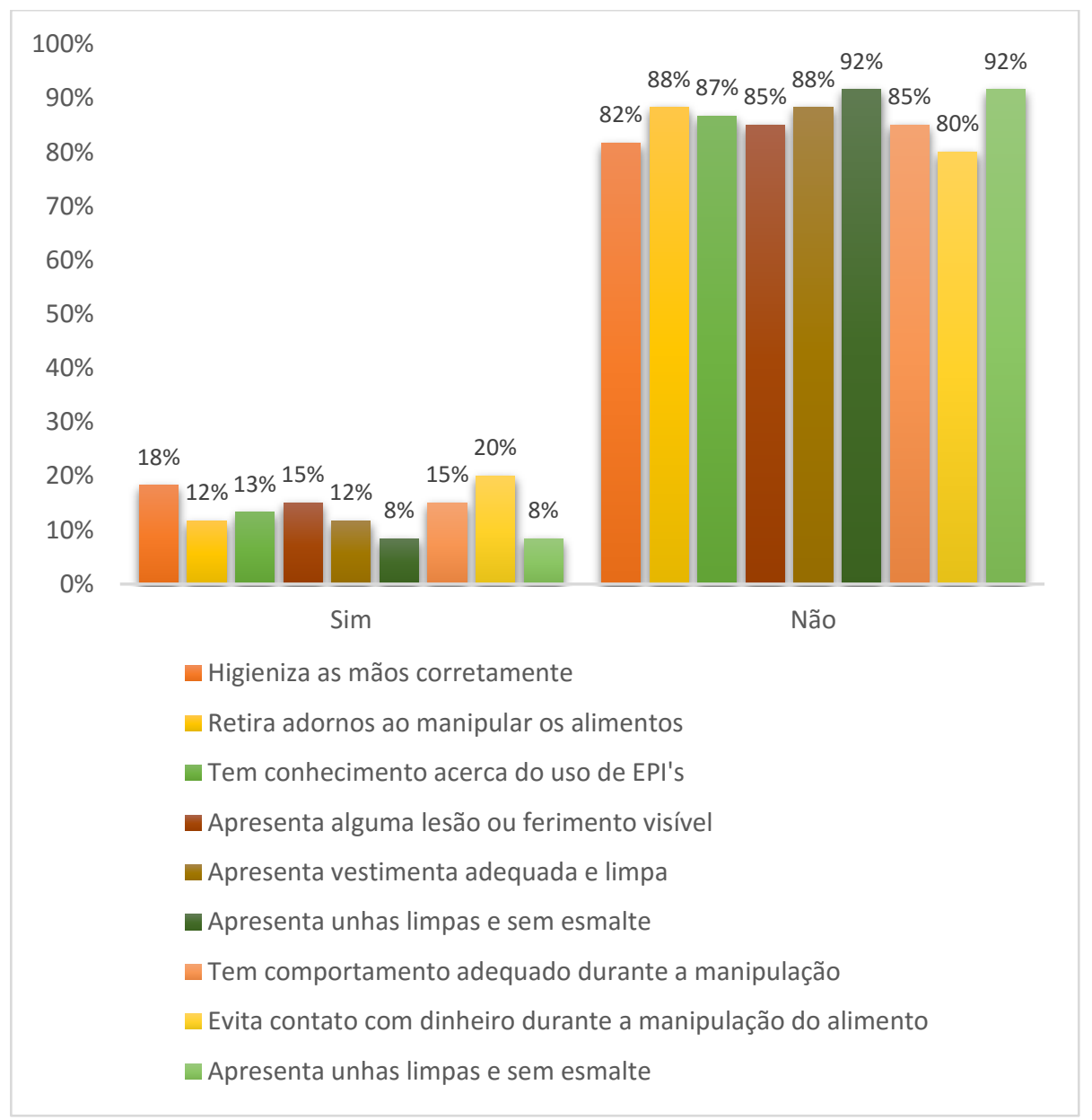

Figura 1. Aspectos gerais de higiene pessoal e comportamento dos manipuladores de camarão regional fresco em feiras e mercados de Belém, PA, Brasil.

Figure 1. General aspects of personal hygiene and behavior of regional fresh shrimp handlers at fairs and markets Belem, PA, Brazil.

Segundo Silva et al., ${ }^{20}$ pescados representam um importante veículo de infecção gastrointestinal em todo mundo, sendo que os manipuladores têm papel importante na veiculação destes patógenos, sendo assim, essencial o cuidado com a higiene pessoal, bem como, a atenção aos procedimentos realizados durante a comercialização do pescado. Montelo et al. ${ }^{21}$ reforçam que capacitações devem ser a ferramenta para promover a segurança, a higiene e a saúde no trabalho qualquer que seja o ramo de atividade, destacando em seu estudo o trabalho informal em feiras livres.

A portaria no $326 / 1997{ }^{19}$ preconiza que os manipuladores não devem fumar, falar desnecessariamente, cantar, assobiar, espirrar, cuspir, tossir, comer, manipular dinheiro ou praticar outros atos que possam contaminar o alimento durante a manipulação. No entanto, estes comportamentos foram observados em $85 \%$ dos pontos de comercialização.

Foi observado também que $80 \%$ dos manipuladores manuseavam dinheiro das compras e o camarão sem a devida higienização das mãos entre uma ação e outra. Silva et al. $^{20}$ ressaltam que mesmo que a existência de uma segunda pessoa para manipulação do dinheiro não seja exigida em legislação este é um ponto a ser observado que contribui para a redução do perigo de contaminação.

Em relação ao ambiente, Germano et al. ${ }^{22}$ destacam que fatores como a presença de animais 
(de estimação, roedores, pássaros ou produtores de alimentos) e demais fatores presentes relacionados à água, solo ou ar constituem potenciais fontes de patógenos.

Ao avaliar estas condições nos mercados e feiras visitados (Figura 2), identificou-se que o acesso de animais de rua (gatos e cachorros) e pragas (insetos e roedores) aos pontos de venda não era possível apenas em dois mercados, no entanto, mesmo nestes ambientes, havia focos de insalubridade (incidência direta de radiação solar sobre produto e funcionários; presença de ruído intenso).

Os camarões em $70 \%$ das observações estavam expostos diretamente a contaminantes físicos (poeira, pelos, sujidades) e em recipientes ou expositores sem capacidades de manter uma temperatura de refrigeração adequada para a venda do camarão fresco. Mendonça et al. ${ }^{23}$ relataram ao analisar alimentos comercializados em feiras livres de Pernambuco que a ausência de balcões refrigerados, vitrines ou correta exposição dos alimentos representam ameaça à saúde do consumidor, pois resultam em exposição excessiva à contaminação. Em anotações tomadas nas observações desta pesquisa, destaca-se ainda o costume popular de pressionar o camarão com os dedos para atestar o seu frescor, praticados por diversos consumidores durante a aplicação da lista de verificação, aumentando de sobremaneira o potencial de contaminações cruzadas.

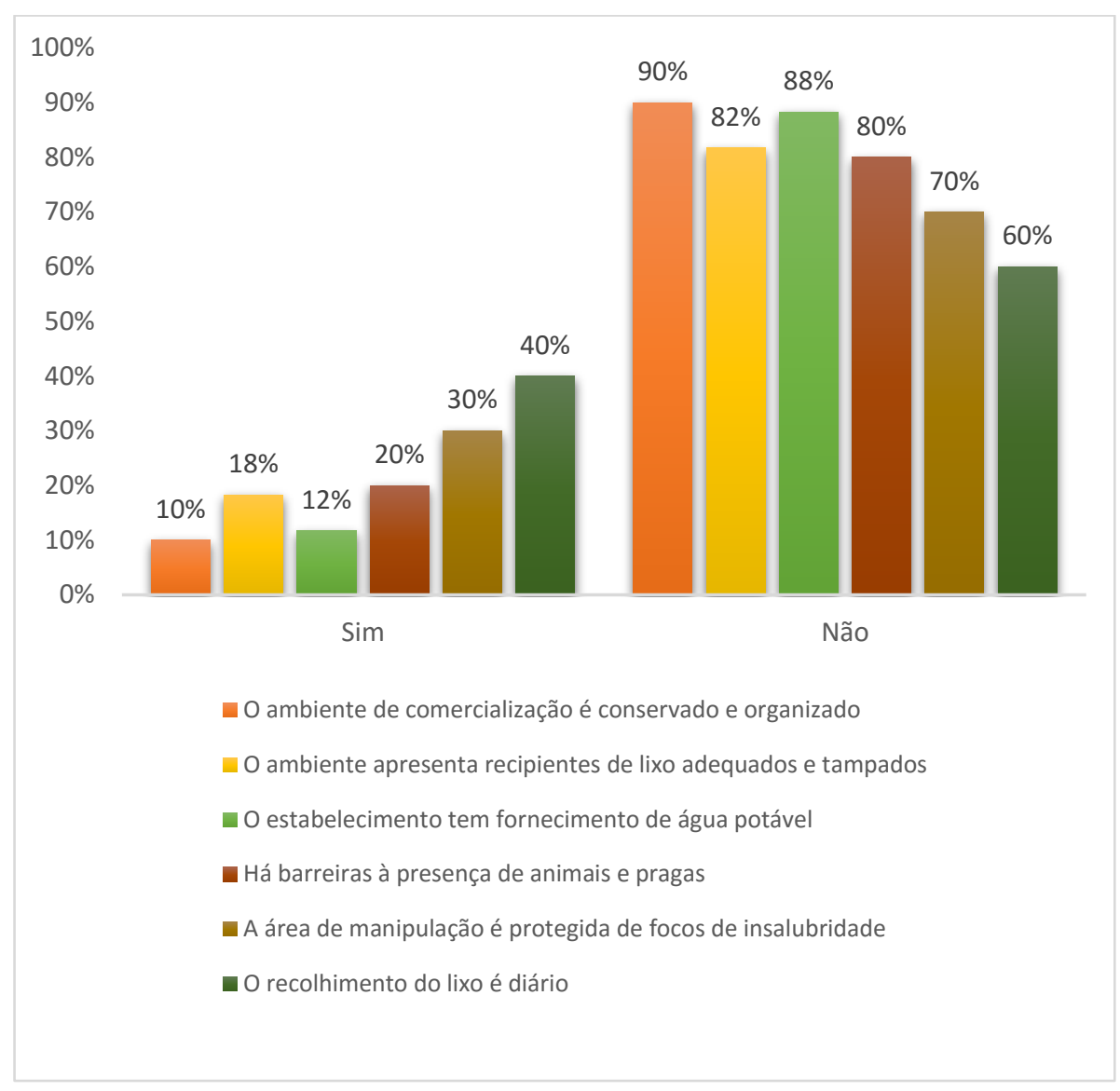

Figura 2. Condições ambientais da área externa dos pontos de comercialização e aspectos gerais das instalações de comercialização e saneamento em feiras e mercados de Belém, PA, Brasil.

Figure 2. Environmental conditions of the external area of marketing outlets and general aspects of marketing facilities and sanitation at fairs and markets Belém, PA, Brazil. 
Verificou-se nos aspectos gerais de instalações e saneamento que $81,7 \%$ das instalações não possuem recipientes de lixo feitos de material apropriado, ou não são adequadamente vedados, convertendo-se assim em focos de mau cheiro e atraindo pragas, o que está em desacordo com o preconizado pela Portaria no $216 / 2004 .^{13}$ Instalações sanitárias precárias ou inexistentes, boxes de manipulação e exposição revestidos de material inadequado e/ou danificado, pisos inadequados e/ou em estado precário de conservação, acúmulo indevido de águas residuais e proximidade a esgotos abertos foram detectados nos estabelecimentos visitados.

Silva et al. ${ }^{20}$ visitando feiras livres em quatro regiões da Grande São Paulo identificaram que as feiras carecem de um melhor equipamento público como, água potável, esgoto sanitário e energia elétrica fornecidos de maneira limpa e segura. Mesmo que a organização e a manutenção da higiene do local de trabalho sejam de responsabilidade do dono do estabelecimento, o fortalecimento de feiras e mercados através de políticas públicas de infraestrutura podem eliminar riscos de contaminação para a população.

Em relação aos aspectos gerais de equipamentos e utensílios, o estado de conservação de equipamentos e/ou utensílios era deficiente (presença de áreas desgastadas, quebradas, sem revestimento adequado/enferrujadas) em $86,7 \%$ das observações.

Inconformidades encontradas foram relacionadas a acúmulo de resíduos e contaminantes, falta de manutenção ou mesmo ausência de protocolos de higienização de rotina adequados, em desacordo com a Portaria no 216/2004. ${ }^{13}$

De acordo com o Manual de Higienização e Sanitização, equipamentos e utensílios devem ser limpos e sanitizados internamente e externamente, antes do uso e depois de cada interrupção de trabaIho. Tais procedimentos não foram observados durante as visitas, no entanto, foram citadas pelos entrevistados, sendo que $10 \%$ declararam realizar limpeza sistemática e frequente das instalações; $6,7 \%$ das superfícies e utensílios e $18,3 \%$ dos equipamentos.

Quanto ao armazenamento dos produtos de limpeza utilizados nos boxes de comercialização, apenas em $8,1 \%$ dos locais onde havia tais produtos, os mesmos encontravam-se armazenados de maneira adequada, sem representar um risco de contaminação química para o produto comercializado.

Não foi observado em nenhum dos boxes de comercialização a presença de aparelhos de refrigeração para armazenamento do pescado (Figura 3), sendo que em $90 \%$ dos estabelecimentos o produto permanece exposto à temperatura ambiente.

Segundo a legislação, ${ }^{7}$ o camarão fresco deve ser mantido em temperatura de refrigeração desde a indústria, incluindo o transporte e mantido resfriado em vitrines fechadas por meio de gelo em escamas de fonte confiável.

Para o produto estocado, apenas em 17 dos 60 estabelecimentos utilizavam gelo para conservação do pescado, e dentre estes, $17,94,1 \%$ dos estabelecimentos que utilizavam gelo o faziam em quantidade ou condições higiênicas precárias. Germano et al. ${ }^{22}$ afirmam que o contato de pescados com gelo de má qualidade é uma forma frequente de contaminação de produtos, veiculando Doenças Transmitidas por Alimentos (DTA's), com destaque às toxinfecções bacterianas.

Figueiredo et al..$^{24}$ e Silva et al. ${ }^{20}$ observaram que em feiras de Cuiabá (MT) e São Paulo (SP) as exigências de temperatura não são atendidas mesmo em estabelecimentos que mantêm o pescado sobre o gelo por falta de treinamento em como dispor corretamente o produto para que haja troca de calor. De maneira semelhante observa-se em feiras e mercados de Belém que há o costume em dispor o camarão sobre o gelo para facilitar a observação por parte do consumidor, sendo este procedimento ineficaz para a manutenção da temperatura.

A ausência de métodos adequados de conservação pelo frio nos pontos de venda é contrária ao descrito na Portaria $n^{\circ} 456^{7}$ que recomenda quanto à preservação do produto, a manutenção da cadeia de frio, assegurando que a parte interna do músculo de pescado seja conservada à temperatura próxima à $0^{\circ} \mathrm{C}$. Em nenhum dos estabelecimentos a exposição para comercialização do camarão foi feita de maneira adequada, estando todas as amostras aferidas acima do $4^{\circ} \mathrm{C}$ em sua forma exposta para a comercialização. 


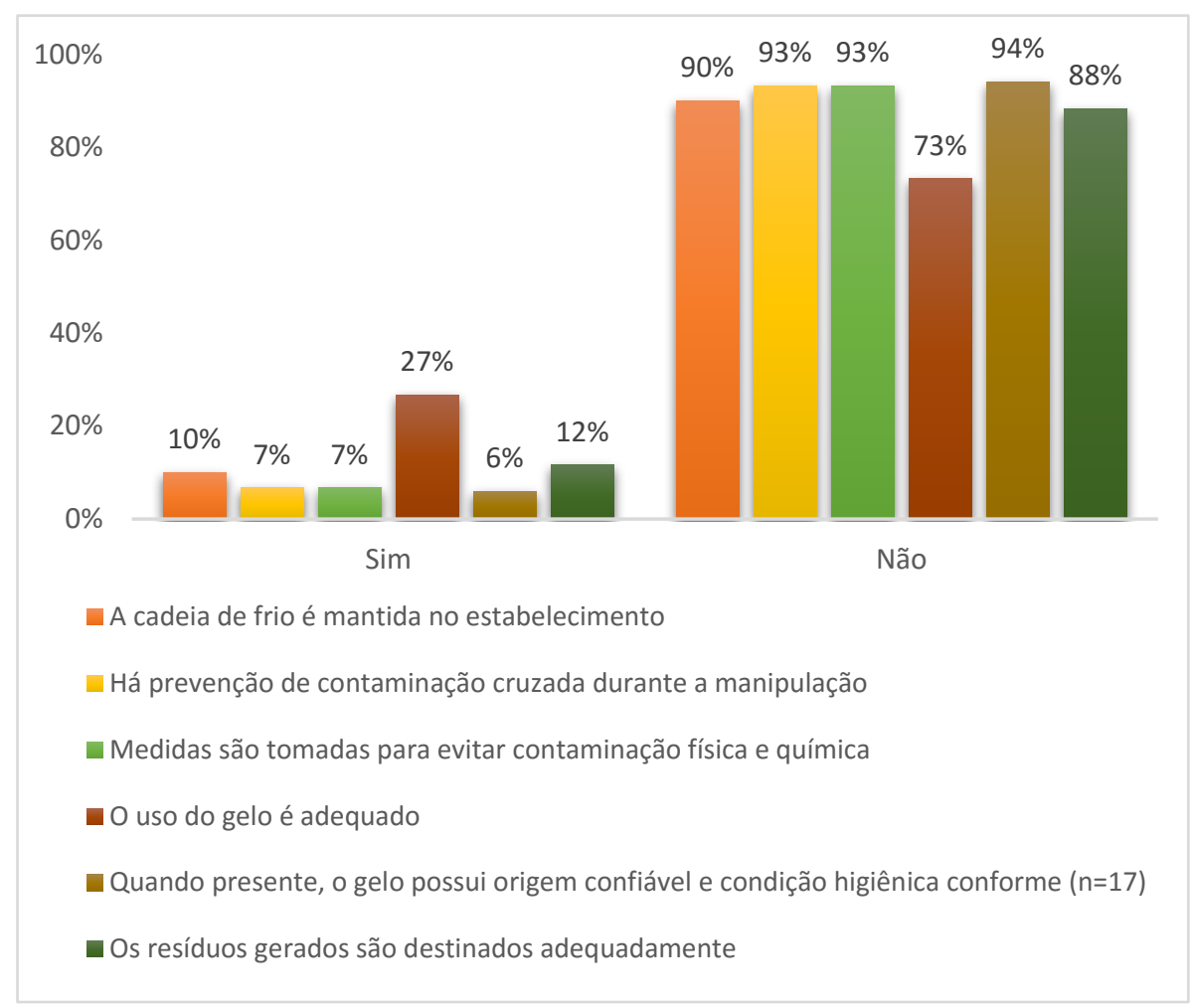

Figura 3. Aspectos gerais de comercialização de camarão fresco em feiras e mercados de Belém, PA.

Figure 3. General aspects of fresh shrimp marketing at fairs and markets Belém, PA, Brazil.

Em relação aos aspectos gerais de equipamentos e utensílios, nenhum dos locais visitados estava conforme a todos os requisitos exigidos pela legislação para comercialização de pescado fresco. A observação estende-se a todos os grupos de parâmetro analisados, assim, nenhum dos estabelecimentos atendeu a Portaria no $216^{13}$ que preconiza a redução, através de agentes químicos ou métodos físicos adequados, do número de micro-organismos no prédio, instalações, maquinários e utensílios, a um nível que não origine contaminação do alimento que será comercializado.

Na maioria dos estabelecimentos o pescado estava exposto em bancadas sem gelo, em bandejas plásticas ou de alumínio, sem proteção quanto a insetos, como moscas, em desacordo mais uma vez com a legislação vigente.

Ao aplicar o coeficiente de correlação de Pearson $(r ; p=0,095)$ às frequências de dados obtidos não foram encontradas correlações significativas, o que mostra que a aplicação de boas práticas não está estatisticamente ligada à idade, sexo ou escolaridade do entrevistado, bem como, não está ligada também à sua participação anterior em capacitações, o que sinaliza uma revisão nas atuais metodologias utilizadas para conscientização deste público.

A lista de verificação utilizada avaliou condições de boas práticas de manipulação em 32 aspectos, registrando $85,9 \%$ de parâmetros inconformes no total dos dados reunidos em todos os estabelecimentos. A média de não conformidades encontradas por estabelecimento foi de $20,6 \pm 2,2$. A lista de verificação empregada neste estudo foi baseada na Resolução RDC no $216^{13}$, de 15 de setembro de 2004 que lista pontos de verificação superficiais de condições higiênico sanitárias. $\mathrm{Na}$ legislação é possível encontrar a RDC $n^{\circ} 275$, de 21 de outubro de $2002^{25}$ que propõe verificações mais abrangentes e que podem ser utilizadas em um estudo mais detalhado de problemas relacionados à manipulação de frutas e hortaliças. Uma sugestão é a sua adaptação para o uso em estabelecimentos manipuladores de pescados e derivados, promovendo assim, não apenas a indicação de não 
conformidades, mas suas possíveis causas levando a estratégias para sua eliminação.

Segundo Lima, ${ }^{4}$ em um estudo similar sobre os aspectos econômicos e higiênico-sanitários da comercialização de camarões de água doce em feiras livres de Macapá e Santana, Estado do Amapá, o número de inconformidades foi semelhante ao encontrado na região metropolitana de Belém no que diz respeito à falta de ordenamento e a falta de higiene das barracas, à exposição do produto, à temperatura ambiente, a não utilização de vestimentas adequadas pelo manipulador e tão pouco fora observado a utilização de gelo ou freezer para armazenamento do camarão, demonstrando que há uma cultura regional de comercialização deste alimento sem devidas precauções com a segurança alimentar do mesmo.

Freire et al. ${ }^{26}$ demonstram em seu trabalho sobre aspectos econômicos e higiênico-sanitários da comercialização do pescado no Município de Bragança (PA) deficiências referentes às boas práticas de manipulação e infraestrutura, que estão associadas às precárias condições higiênico-sanitárias das feiras livres ali avaliadas. Ainda no Estado do Pará, Brandão et al. ${ }^{27}$ detectaram inúmeras irregularidades no âmbito higiênico-sanitário dos produtos cárneos e pescados vendidos frescos nas feiras livres da região concluindo que estas podem comprometer a saúde dos consumidores do município de Santarém.

Entretanto, as más condições higiênicas sanitárias de feiras livres não condizem a uma realidade somente da Região Norte do país, Moura ${ }^{28}$ mostrou em sua pesquisa realizada na cidade de Fortaleza (CE) várias irregularidades no âmbito de instalações e equipamentos, assim como não atendiam aos requisitos mínimos exigidos nas normas sanitárias para a exposição e comercialização do pescado.

Tais irregularidades repetem-se no trabalho de Holanda et al. ${ }^{29}$ que discorre acerca da avaliação das condições higiênico-sanitárias das feiras livres de comercialização de peixe na cidade de Caxias (MA), os autores se depararam com uma realidade que se repete nos demais locais mencionados anteriormente, onde os produtos comercializados impõem risco à saúde do consumidor apresentando condições insatisfatórias e não conformidades com alguns parâmetros para manipulação de alimento e elucidando a importância a utilização das boas práticas de manipulação para comercialização dos produtos frescos, principalmente pescado.
Santos et al. ${ }^{30}$ pesquisando estabelecimentos de venda em Aracaju, encontraram dados semeIhantes e afirmaram que a solução para controlar riscos potenciais à saúde do consumidor passam por medidas higiênico-sanitárias mais rigorosas e adoção e aplicação de boas práticas.

Martins ${ }^{31}$ citou que em Vitória (ES) foi regulamentada uma padronização das feiras livres, onde as barracas de pescado devem conter balcões de exposição com limpeza constante e os peixes expostos devem ficar permanentemente em gelo para garantir o resfriamento. Além disso, os resíduos orgânicos gerados na limpeza do pescado devem ser acondicionados em sacos plásticos e depois transportados para os locais disponibilizados para este fim. Esta experiência tem suscitado significativas mudanças na qualidade do pescado consumido pela população desta região.

\section{CONCLUSÕES}

Todos os estabelecimentos visitados durante essa pesquisa apresentaram não conformidades em pelo menos um dos aspectos de manipulação e comercialização analisados, estado assim, em desacordo com requisitos preconizados pela legislação, tanto em relação às instalações, equipamentos e utensílios, quanto na questão da higiene pessoal e acondicionamento do produto, acrescentando riscos à saúde do consumidor. Tais irregularidades devem-se pela falta de noções de Boas Práticas de Manipulação, reforçando a necessidade de capacitação, conscientização e fiscalização intensiva das feiras e mercados da região metropolitana de Belém, bem como campanhas educativas que visem a conscientização dos consumidores.

\section{CONTRIBUIÇÃO DOS AUTORES}

Os autores GLCA e HCAK participaram na condução do experimento, análise dos dados e elaboração do artigo científico.

\section{CONFLITO DE INTERESSE}

Os autores declaram que não há conflito de interesse.

\section{FINANCIAMENTO}

Os autores reportaram que não houve suporte e auxílio financeiro durante o desenvolvimento da pesquisa. 


\section{COMO CITAR ESSE DOCUMENTO}

\section{ABNT}

de ALCÂNTARA, Gisélia de Lourdes Cardoso; KATO, Hellen Christina de Almeida. Boas práticas de manipulação na comercialização do camarão fresco em feiras livres de Belém, PA. Journal of bioenergy and food science, v.3, n.3, p.139-148, 2016. DOI:10.18067/jbfs.v3i3.98

\section{APA}

de Alcântara, G., \& Kato, H. (2016). Boas práticas de manipulação na comercialização do camarão fresco em feiras livres de Belém, PA. Journal Of Bioenergy And Food Science, 3(3) 139-148. DOI:10.18067/jbfs.v3i3.98

\section{REFERÊNCIAS BIBLIOGRÁFICAS}

1. MACIEL, C. R.; VALENTI, W. C. Biology, Fisheries, and Aquaculture of the amazon River Prawn Macrobrachium amazonicum: A Review. Nauplius, v.17, p.61-79, 2009.

2. BRASIL. Ministério da Pesca e Aquicultura. Boletim estatístico da pesca e aquicultura. Brasília (DF), 2013. $60 \mathrm{p}$.

3. ROCHA, C. P. Fecundidade do camarão-da-Amazônia, Macrobrachium amazonicum (Heler, 1862) (decapoda: palaemonidae) em dois ambientes estuarinos no Estado do Pará. 2010. 55p. Dissertação (Mestrado em Ciência Animal) - Universidade Federal do Pará, Embrapa Amazônia Oriental, Universidade Federal Rural da Amazônia, Belém, 2010.

4. LIMA, J. F.; SANTOS, T. S. Aspectos econômicos e higiênico-sanitários da comercialização de camarões de água doce em feiras livres de Macapá e Santana, Estado do Amapá. Biota Amazônia, v.4, n.1, p.1-8, 2014. DOI 10.18561/2179-5746/biotaamazonia.v4n1p1-8

5. LIRA, G. M.; PEREIRA, W. D. Avaliação da qualidade de peixes comercializados na cidade de Maceió, AL. Higiene alimentar, v.15, n.84, p.67-74, 2001.

6. LUNDGREN, U. P. Perfil da qualidade higiênicosanitária da carne bovina comercializada em feiras livres e mercados públicos de João Pessoa/PB -Brasil. Revista Verde, v.7, n.1, p.225-232, 2012.

7. BRASIL. Ministério da Agricultura, Pecuária e Abastecimento. Portaria $n^{\circ} 456$ de 10 de Setembro de 2010. Aprova o Regulamento Técnico de Identidade e Qualidade para Camarão Fresco. Brasília (DF), 2010.

8. BARBOSA, J. A.; SANTANA, A. C.; SILVA, I. M.; BOTELHO, M. N.; CONDURÚ NETO, J. M. H. Características comportamentais do consumidor de peixe no mercado de Belém. Boletim Técnico Científico do Cepnor, v.7, n.1, p.115-133. 2013.

9. SOUSA, C. O.; CHAVES FILHO, G. P.; MELO, K. K. F.; FERNANDES, M. B.; ROCHA, S. F.; MACHADO, A. L. Perfil da qualidade higiênico-sanitária de carnes comercializadas no município de Pau de Ferros/RN Brasil. In: VII Congresso Norte e Nordeste de Pesquisa e Inovação, Palmas, 2012. Anais... Palmas: IFTO, 2012.

10. CHAVES, D.C. Condições higienicas e sanitárias da feira livre do bairro São Francisco no município de Zé Doca - MA.In: 5o Congresso Brasileiro De Quimica - Meio Ambiente E Energia, São Luis, 2011. Anais... São Luís: CBQ, 2011.

11. MONTEIRO, G. N. A., Aplicação de check-list para avaliação das condições de comercialização de carne suína nas feiras livres de Belém-PA. In: XXIV Congresso Brasileiro de Zootecnia, 2014, Vitória - ES. Anais... Vitória: ABZ, 2014.

12. CORREIA, M.; RONCADA, M. J. Características microscópicas de queijos prato e mussarela e mineiro comercializados em feiras livres da cidade de São Paulo. Revista de Saúde Pública, v.31, n.3, p.296-301, 1997.

13. BRASIL. Agência Nacional de Vigilância Sanitária. Resolução da Diretoria Colegiada (RDC) no 216 do Ministério da Saúde, 2004. Diário Oficial da União, Brasília (DF), 2004.

14. TOMICHI, P. G. R. Metodologia para avaliação das Boas Práticas de fabricação em indústrias de pão de queijo. Ciência e Tecnologia dos Alimentos, Campinas, v.2, n.1, p.115-120, 2005.

15. BRASIL. Ministério da Agricultura, Pecuária e Abastecimento. Portaria n. 46, de 10 de fevereiro de 1998. Institui o sistema de análise de perigos e pontos críticos de controle: APPCC a ser implantado nas indústrias de produtos de origem animal. Diário Oficial da União, Brasília (DF), 1998.

16. FURTINI, L. L. R.; ABREU, L. R. Utilização do APPCC na Indústria de Alimentos. Revista Ciência Agrotecnológica, Lavras, v.30, n.2, p. 358-363, 2006.

17. SILVA, D.P. Qualidade no gerenciamento de projeto. Niterói: Universidade Cândido Mendes, 2010.

18. NÓBREGA, G. S.; MARTINS, V. L. A.; PENA, P. G. L.; MARTINS, Y. D.; SEIXAS JM, GOMES TMD, GOÉS H.T S. Formação para marisqueiras em segurança de alimentos e saúde do trabalhador: uma experiência na comunidade de llha do Paty Bahia, Brasil. Ciência \& Saúde Coletiva, v.19, n.5, 2014. DOI 10.1590/1413-81232014195.03772013

19. BRASIL. Ministério da Saúde. Secretaria de Vigilância Sanitária. Portaria no 326 de 01 de agosto de 1997. Aprova o Regulamento Técnico de Identidade e Qualidade de Peixes Frescos (inteiro e eviscerado). Brasília (DF), 1997.

20. SILVA, M. L.; MATTÉ, G. R.; MATTÉ, M. H. Aspectos sanitários da comercialização de pescado em feiras livres da cidade de São Paulo, SP/Brasil. Revista do Instituto Adolfo Lutz, v.67, n.3, p.208-214, 2008. 
21. MONTELO, R. O.; MARTINS, G. A. S. M.; TEIXEIRA, S. M. F. Avaliação das condições de segurança e higiene do trabalho: Estudo de caso na feira livre do agricultor em Palmas - Tocantins. UNOPAR Científica Ciências Biológicas Saúde, v.13, n.4, p. 263-70, 2011.

22. GERMANO P. M. L.; OLIVEIRA, J. C. F.; GERMANO, M. I. S. O pescado como causa de toxinfecções bacterianas. Revista Higiene Alimentar, v. 7, n. 28, p. 40-44, 1993.

23. MENDONÇA, S. C.; CORREIA, R. T. P.; ALBINO, E. Condições higiênico sanitárias de mercados e feiraslivres da cidade de Recife-PE. Higiene Alimentar, v.16, n.94, p.20-25, 2002.

24. FIGUEIREDO, E. S. E.; IMBELLONI, M. F.; ELESBÃO, H. S.; SANTOS, A. F. Avaliação das condições Higiênicosanitárias de manipulação de comercialização de produtos de origem animal nas feiras livres do município de Cuiabá - MT. Revista Higiene Alimentar, v.21, n.148, p.38-42, 2007.

25. BRASIL. Agência Nacional de Vigilância Sanitária. Resolução da Diretoria Colegiada (RDC) no 275 do Ministério da Saúde, 2002. Diário Oficial da União, Brasília (DF), 2002.

26. FREIRE, J. L.; SILVA, B. B.; SOUZA, A. S. Aspectos econômicos e higiênico sanitários da comercialização de pescado no Município de Bragança (PA). Biota Amazônia, Macapá, v.1, n.2. p. 17-28, 2011. DOI 10.18561/2179-5746/biotaamazonia.v1n2p17-28
27. BRANDÃO, B. P.; VINENTE NETO, B. F.; PONTES, D. F.; CARVALHO, J. A. S.; LEAL, J. F. S.; Quaresma, T. C. Agravantes ambientais que influenciam na carne e no pescado do mercado municipal de Santarém-PA. Em Foco, v.11 n.21, 2014.

28. MOURA, A. F. P. A Qualidade dos alimentos no contexto da política de segurança alimentar: estudo de caso numa feira livre tradicional de Fortaleza. 2007. 114p. Dissertação (Mestrado em Planejamento e Políticas Públicas) - Universidade Estadual do Ceará, Fortaleza, 2007.

29. HOLANDA, M. F. A. SILVA, M. A. M. P.; PINTO, L. I. F.; BRANDÃO, T. M.; SILVA, R. A. Avaliação das condições higiênico-sanitárias das $f$ eiras livres de comercialização de peixe na cidade de Caxias-MA. Acta Tecnológica, v.8, n.2, p.30-35, 2013.

30. SANTOS, A. A. ; SIMÕES, G. T. N.; CRUZ, M. M.; FERREIRA, N. S. S.; LIMA, R. T. C.; TUNON, G. I. L. Avaliação da qualidade microbiológica de sushi comercializado em restaurantes de Aracaju. Scentia Plena, v. 8, n.3, p. 1-4, 2012.

31. MARTINS, R. G. Projeto Qualifeiras. In: IV Seminário Estadual de Saneamento e Meio Ambiente, 2003, Vitória - ES. Anais... Vitória: Associação Brasielira de Engenharia Sanitária e Ambiental - ABES, 2003. 